\title{
Dielectric and mechanical assessment of cellulosic insulation during transformer manufacturing
}

\author{
Jaime Sanz \\ Electrical and Energy \\ Engineering Department \\ University of Cantabria \\ Santander, Spain \\ uc26239@alumnos.unican.es
}

\author{
Oasis Sancibrián \\ Electrical and Energy \\ Engineering Department \\ University of Cantabria \\ Santander, Spain \\ oasis.sancibrian@unican.es \\ Carlos Vila \\ Department of Standarization and \\ Maintenance of Transformers \\ Iberdrola \\ Madrid, Spain \\ cvila@iberdrola.es
}

\author{
Inmaculada Fernández \\ Electrical and Energy \\ Engineering Department \\ University of Cantabria \\ Santander, Spain \\ inmaculada.fernandez@unican.es \\ Cristina Méndez \\ Electrical and Energy \\ Engineering Department \\ University of Cantabria \\ Santander, Spain \\ cristina.mendez@unican.es
}

\author{
Alfredo Ortiz \\ Electrical and Energy \\ Engineering Department \\ University of Cantabria \\ Santander, Spain \\ alfredo.ortiz@unican.es
}

\begin{abstract}
Due to the impact of cellulose of paper insulation on transformer life, it is imperatire to remove moisture from the oil and the solid insulation. Several techniques have been implemented during manufacturing of power transformers to reduce water content in transformers. These drying processes can involve different costs and time, and they can damage the insulation paper. In this work, a drying process has been implemented in the laboratory trying to simulate the most aggressive conditions that can be suffered by the paper in transformer manufacturing in a real industry. Then the effect of the drying process on paper was evaluated using the analysis of mechanical and dielectric properties and the degree of polymerization. Different commercial papers were studied to quantify the possible degradation induced by the drying process. The results of the mechanical strength study showed a reduction on the degree of polymerization from 1100 to 850 after 4 days of drying. The dielectric analysis of the samples showed different behavior in one of the solids evaluated and it was also found a decreased hygroscopic capacity of degraded samples in comparison with new samples.
\end{abstract}

Keywords - dielectric analysis, degree of polymerization, cellulosic insulation, moisture, drying

\section{INTRODUCTION}

Power transformers are essential components in electrical power transmission systems. In oil immersed power transformers, the insulation system is a combination of an insulating fluid and impregnated cellulosic paper on the copper windings and pressboard between the high and low-voltage windings and between those and the core [1].

The insulation system is designed to guarantee its dielectric behaviour under normal operating conditions. However, even this situation causes a gradual deterioration of insulation. Both the liquid and solid insulation are subjected to different stresses: temperature, moisture, oxygen, vibrations, electric fields, etc. [2]. Insulating paper subjected to high temperatures degrades rapidly due to oxidative processes and hydrolysis. Both the oxidation and hydrolysis lead to cellulose oxidation, depolymerisation and recrystallization which rise to the loss of the mechanical resistance [3] which may lead to electric breakdown ending up in power transformer failure.

Although transformers gain moisture once in service from external sources and cellulose deterioration due to heat, a proper drying process down to $0.5 \%$ moisture during manufacturing increases long life expectancy of power transformers [4]. Water in the insulation liquid and solid reduces the dielectric strength of both, and has adverse effects on aging rates and the dielectric integrity of insulation [5], [6]. Consequently, it is desirable to produce transformers with their insulation system as dry as it is reasonably possible.

The drying process of power transformers has a critical effect on their quality and lifetime, so the elimination or reduction of moisture is a challenge for power transformers manufacturers, who have implemented different technologies to diminish water in insulation solid [7]: hot air, hot air with rough vacuum, vacuum drying oven, oil circulation, oil spray, vacuum pressure impregnation and vapor phase drying (VPD). However, currently the length of the drying process is still too often based on manufacturer experiences and empirical procedures. Drying process tries to remove water vapor and air in the paper interstices before the impregnation process [8]. Improper drying may generate partial discharges, the increase of dielectric dissipation factor and the decrease of breakdown voltage, as well as the degradation and accelerated aging of the insulation system.

In this context, this paper has aimed to analyze the deterioration suffered by different commercial insulation solids used in power transformers, during a drying process using different techniques: degree of polymerization, tensile testing, and dielectric analysis. Due to the influence of moisture on dielectric properties, the moisture content of the samples needed to be determined. Internal water saturation curves were measured for samples after the drying process. The dielectric 
analysis was also performed on new samples conditioned to different relative humidity.

In summary, dielectric response together with moisture and mechanical resistence analysis were used to determine the effect of the drying process on different commercial papers used in power transformers manufacturing.

\section{EXPERIMENTAL}

\section{A. Samples}

For this study, three insulation papers were used, Kraft $(180 \mu \mathrm{m})$, Diamond Dotted Paper (DDP, $200 \mu \mathrm{m})$ and pressboard (PSP, $500 \mu \mathrm{m})$.

The papers were cut into $7 \mathrm{~cm}$ square pieces for dielectric analysis and into strips of $26 \mathrm{~cm} \mathrm{x} 1.5 \mathrm{~cm}$ for tensile test. Due to paper anisotropy [9]-[11], the strips were cut with two different fiber direction angles (longitudinal and transverse) to measure mechanical properties (tensile strength, strain, energy per unit volumen...).

\section{B. Paper drying}

The drying process was carried out in the laboratory at constant temperature of $120^{\circ} \mathrm{C}$ and atmospheric conditions. The drying process consisted of the following steps trying to simulate a real drying process implemented in a company during manufacturing.

- $\quad$ Drying I: Two days in a $120^{\circ} \mathrm{C}$ fan oven.

- $\quad$ Rest I: One day in ambient conditions $\left(23^{\circ} \mathrm{C}\right)$

- Drying II: Two days in a $120^{\circ} \mathrm{C}$ fan oven.

- $\quad$ Rest II: One day in ambient conditions $\left(23^{\circ} \mathrm{C}\right)$

- Drying III: Two days in a $120^{\circ} \mathrm{C}$ fan oven.

In transformer manufacturing the last stage of hot air drying is replaced by VPD drying. Even so, it was incorporated into this study to better observe the degradation of the paper and the effect of long drying times.

\section{Analitical procedures}

One of the most commonly used methods for measuring cellulose degradation involves the determination of the degree of polymerisation. In this work, the average viscometric degree of polymerization (DP) was determined according to ASTM D4243 standard, based on measurements at $20^{\circ} \mathrm{C}$ with an automatic viscometer equipped with a two-sphere Ubbelohde tube. To this effect, the paper was shredded and dissolved in a solution of deionised water and bis(ethylenediamine) copper (II) hydroxide. After dissolution of the paper in the prepared solution, its specific viscosity was determined and used to obtain the DP.

Tensile testing was chosen to evaluate the loss of mechanical resistance suffered by paper and pressboard during the drying process. In this work, a universal servohydraulic test machine Model ME-405-1 SERVOSIS was used to obtain load and displacement data, from which the stress-strain curve was computed using the original specimen cross-sectional area. The length of the paper strips for the measurement of the strain was set at $180 \mathrm{~mm}$ and the rate of separation of the grips was

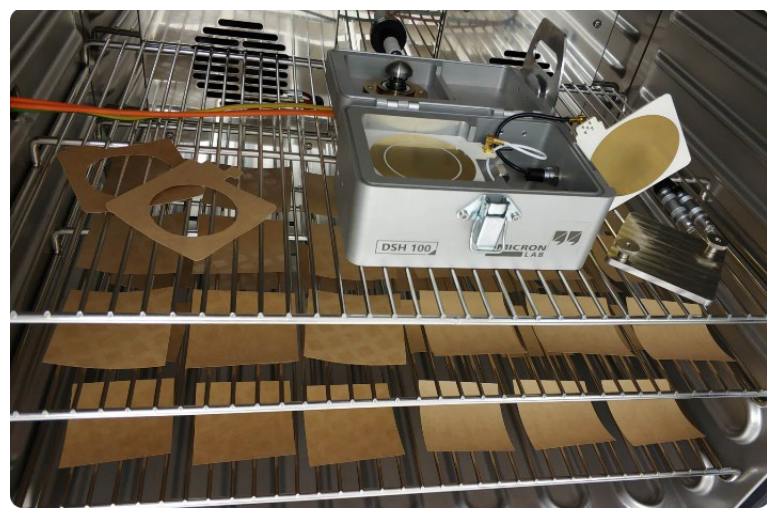

Fig. 1. Dielectric Material Analyzer with paper samples inside the climate chamber.

established at $20 \mathrm{~mm} / \mathrm{min}$ until sample rupture, in accordance with ISO 1924-2:2008 standard.

The paper samples were conditioned at $23 \pm 0.5{ }^{\circ} \mathrm{C}$ and $50 \pm 1 \%$ relative humidity for 4 days, according to IEC 62631 1:2011. The dielectric tests were performed under the same ambient conditions.

The dielectric properties analysis focused on the relative complex permittivity and mainly on the dielectric dissipation factor $(\tan \delta)$. For this purpose, the material analyzer SPECTANO 100 was used in combination with the dielectric sample holder DSH 100. This equipment uses the Dielectric Response/Spectroscopy in Frequency Domain (FDS) and the Polarization/Depolarization Current (PDC) methods. This dielectric study was carried out with a frequency range from $17 \mathrm{mHz}$ to $5 \mathrm{kHz}$.

Finally, due to the influence of moisture on dielectric properties, the moisture content of the samples was determined by drying to constant mass in a fan oven at $105^{\circ} \mathrm{C}$. Internal water saturation curves were measured in the solid samples after the drying process to verify if the lower hygroscopic capacity upheld at different conditions of temperature and relative humidity.

\section{RESULTS}

This section shows the degradation suffered by the insulation papers considered in this work.

\section{A. Moisture analysis}

The internal moisture results of new and aged (dried 8 days) samples after reaching the equilibrium under test conditions are collected in Table I. The hygroscopic capacity of all the materials was reduced after the drying process. This decrease is an evidence of the aging of solid insulation [12].

TABLE I. RESUlTS FROM MOISTURE ANALYSIS ON CONDITIONED SAMPLES

\begin{tabular}{|c|c|c|c|c|c|}
\hline \multirow{2}{*}{ Paper } & \multicolumn{2}{|c|}{ Initial moisture } & \multicolumn{2}{c|}{ Aged moisture } & \multirow{2}{*}{$\begin{array}{c}\text { Moisture } \\
\text { loss }\end{array}$} \\
\cline { 2 - 5 } & Mean (wt\%) & $s d(w t \%)$ & Mean (wt\%) & $s d(w t \%)$ & $4 \%$ \\
\hline DDP & 5.88 & 0.10 & 5.66 & 0.02 & $4 \%$ \\
\hline Kraft & 6.92 & 0.03 & 6.17 & 0.08 & $11 \%$ \\
\hline PSP & 6.72 & 0.01 & 6.24 & 0.01 & $7 \%$ \\
\hline
\end{tabular}




\section{B. Dielectric Response}

The dielectric response of Kraft paper and PSP showed a shift of the Tan $\delta$ curve from left to right of the frequency axis with the internal moisture content increase (Fig. 2). Also, it has been noticed a small vertical shift, since the minimum and maximum points of the curve were slightly higher in the samples with higher internal moisture.

However, a different dielectric behavior was found in diamond pattern coated insulation paper. The dielectric losses curve remained almost constant in the dried samples in comparison with the new ones, despite the reduction of moisture content. The main different between Kraft and DDP samples is the epoxy resin of the last one. During the drying process, epoxy coating was affected. The deterioration of this material may have caused the change on the dielectric response pattern. The effect of the reduction of internal moisture content was countered by the aging of epoxy resin.

In order to gain a better understanding of DDP behavior, new samples were conditioned to different relative humidity. Dielectric tests were performed with these new samples and they all verified the right-shift of Tan $\delta$ curve (Fig. 3), concluding that the difference in behavior of DDP in comparison with Kraft and PSP is due to the presence of epoxy.

\section{Degree of polymerization}

DP tests showed the damaging effect of the drying process on the internal structure of the solid insulation, as can be seen in Fig. 5. In this figure the results have been normalized dividing the DP by the initial value for each paper, to facilitate visualization.

After only two days of drying, DP of paper samples was reduced by around $15 \%$ with respect to the initial value (1100 on average). With four days of drying, DP fell to 850 on average, meaning a $23 \%$ reduction from the initial value. When considering the complete drying process, DP fell up to $34 \%$. PSP withstood the drying process better than the Kraft and DDP samples, especially at the beginning of the drying. The aging was more significant in the Kraft paper, which is in concordance with the loss of hygroscopic capacity, as explained in section III.A.

Fig. 6 shows the progressive reduction of the DP of the PSP with the drying time, and how it directly relates to the loss of hygroscopic capacity of the paper.

\section{Mechanical Strength Analysis (Stress-strain Analysis)}

Mechanical strength tests were performed with Kraft and DDP samples, since PSP was not compatible with the test machine. Results showed that the samples lost deformation capacity due to the drying process (Fig. 7). The longer this process, the lower deformation was withstood by the samples. Nevertheless, the rupture strength was slightly higher in the aged papers, probably caused by the smaller deformation in comparison with the untreated samples. DDP showed a higher mechanical strength than the Kraft paper, even at the new state.

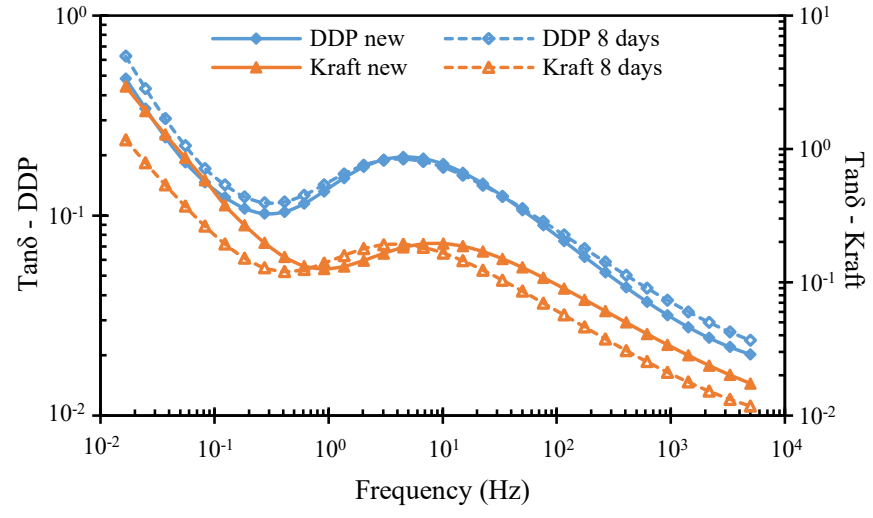

Fig. 2. Tan $\delta$ curves comparing new and aged DDP and Kraft papers.

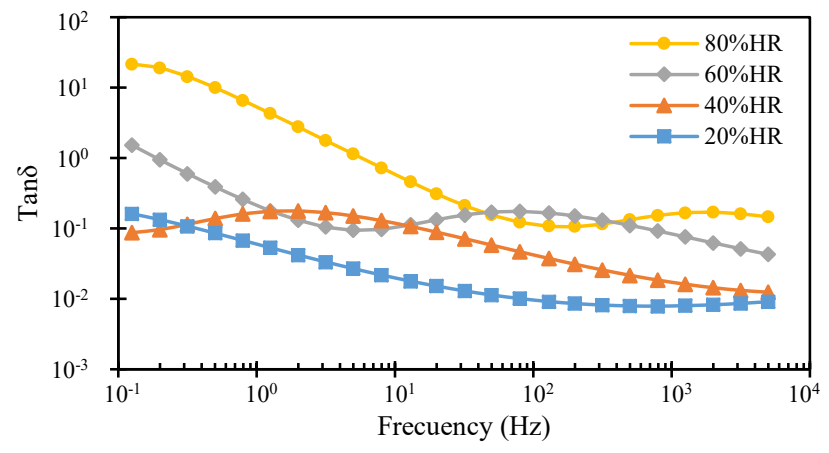

Fig. 3. Tan $\delta$ curves of DDP conditioned to different relative humidity.

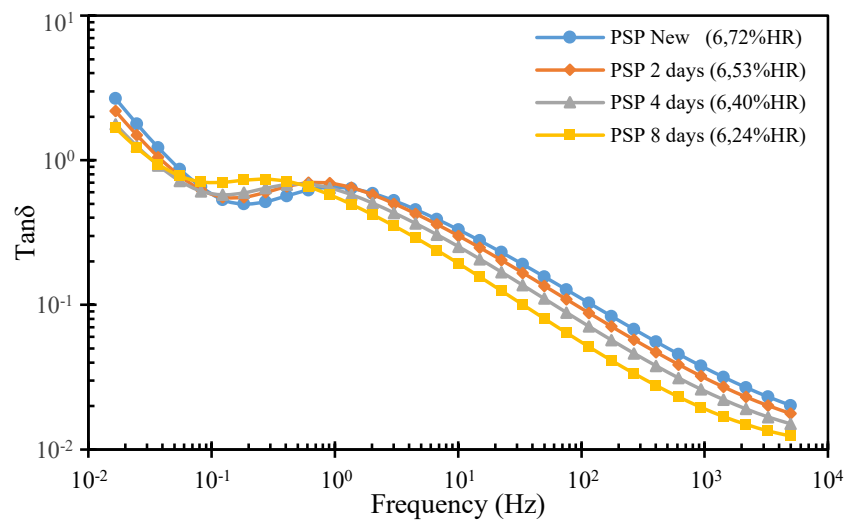

Fig. 4. Tan $\delta$ curves of PSP paper subjected to different drying times.

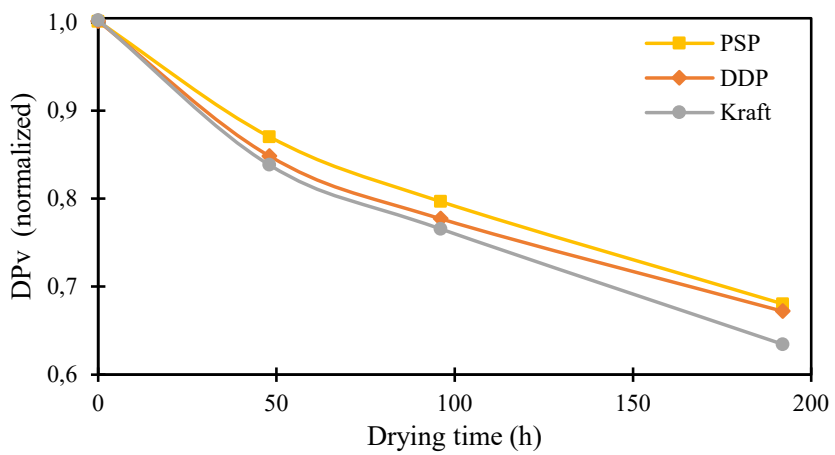

Fig. 5. DP measurements at different stages of the drying process. 


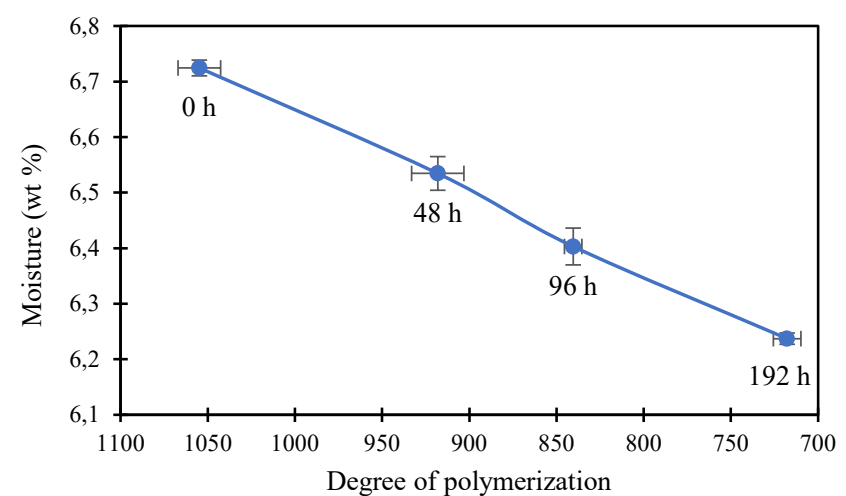

Fig. 6. Moisture and DP analysis on PSP paper with different drying times

\section{CONCLUSIONS}

In this work, the effect of the drying process on the dielectric properties, degree of polymerization and mechanical strength of Kraft, DDP and PSP samples have been analyzed.

New and dry samples were conditioned under controlled ambient conditions. After that, water content was measured. Results showed a lower hygroscopic capacity of the aged samples in comparison with the new ones, which results in a reduction of the internal moisture.

The dielectric analysis was performed after the conditioning period. Kraft and PSP samples showed a horizontal ship of $\tan \delta$ curve, which moves from left to the right of the frequency axis with the aging of the samples. This behavior is explained by the reduction of moisture content of the samples. On the contrary, DDP curves did not show a significant change. Dielectric tests were also performed on new samples conditioned to different relative humidity. The results tested the effect of moisture on the right shift of the curve. This allowed as to conclude that the different behavior of DDP was caused by the changes of the epoxy resin, which counter the effect of moisture reduction in the aged samples.

To verify the conclusion drawn from the moisture and dielectric results, DP of all the samples was measured. All the solids studied suffered a reduction of DP with the drying process.

All the results were in concordance with the mechanical strength tests. The samples subjected to the drying process exhibited a lower deformation capacity than the new ones.

\section{ACKNOWLEDGMENT}

This research is under the National Research Project "Gestión del Ciclo de Vida de Transformadores Aislados con Fluidos Biodegradables" (PID2019-107126RB-C22/ AEI / $10.13039 / 501100011033)$. The authors also wish to thank "Fundacion Iberdrola" for its financial support for the research project: "Análisis de las Propiedades Dieléctricas de Aislamientos Sólidos Impregnados con Líquidos Dieléctricos". C. Méndez would like to acknowledge the Spanish Ministry of Science, Innovation and Universities for the financial support for the FPU grant (FPU19/01849).

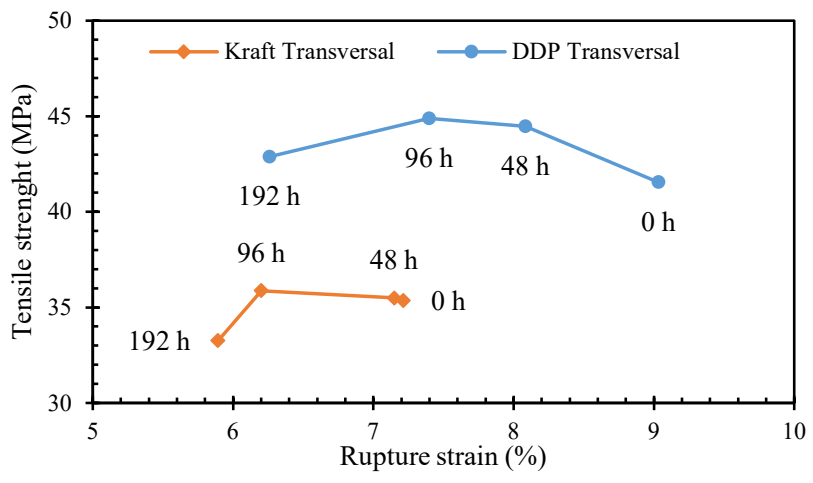

Fig. 7. Results from testile testing on DDP and Kraft paper.

\section{REFERENCES}

[1] D. Linhjell, L. Lundgaard, and U. Gäfvert, "Dielectric response of mineral oil impregnated cellulose and the impact of aging," IEEE Trans. Dielectr. Electr. Insul., vol. 14, no. 1, pp. 156-169, 2007.

[2] J. S. N'Cho, I. Fofana, and A. Beroual, "Parameters affecting the static electrification of aged transformer oils," in Annual Report Conference on Electrical Insulation and Dielectric Phenomena, CEIDP, 2011.

[3] J. Bagniuk et al., "How to estimate cellulose condition in insulation transformers papers? Combined chromatographic and spectroscopic study," Polym. Degrad. Stab., vol. 168, 2019.

[4] G. R. Steeves, "Vapor phase transformer drying - Part I," Transformers Magazine, 2016.

[5] W. S. Zaengl, "Dielectric Spectroscopy in Time and Frequency Domain for HV Power Equipment, Part I: Theoretical Considerations," IEEE Electr. Insul. Mag., vol. 19, no. 6, pp. 9-22, 2003.

[6] W. S. Zaengl, "Applications of dielectric spectroscopy in time and frequency domain for HV power equipment," IEEE Electr. Insul. Mag., vol. 19, no. 6, pp. 9-22, 2003.

[7] M. Tareq Siddiqui, J. T. Pattiwar, and A. P. Paranjape, "Vapor Phase Drying for Moisture Removal from Transformer Coil Insulation," Int. J. Sci. Eng. Res., vol. 8, no. 4, pp. 20-24, 2017.

[8] A. Betie, F. Meghnefi, I. Fofana, and Z. Yeo, "Thermogravimetric Analyses,” Energies, vol. 11, no. 3, pp. 1-15, 2018.

[9] C. Fernández-Diego et al., "Damage assessment of transformer Kraft paper insulation aged in mineral and vegetable oils," Cellulose, vol. 26, no. 4, pp. 2653-2672, 2019.

[10] I. Carrascal, C. Fernández, J. A. Casado, S. Diego, I. Fernández, and A. Ortiz, "Quantification of Kraft paper ageing in mineral oil impregnated insulation systems through mechanical characterization," Cellulose, vol. 25, pp. 3583-3594, 2018.

[11] I. L. Hosier, P. L. Lewin, J. Pilgrim, and G. Wilson, "Effects of aging on the mechanical and dielectric properties of transformer grade Kraft paper," 2020 IEEE Electr. Insul. Conf. EIC 2020, pp. 317-320, 2020.

[12] P. Przybylek, "The influence of temperature and aging of cellulose on water distribution in oil-paper insulation," IEEE Trans. Dielectr. Electr. Insul., vol. 20, no. 2, pp. 552-556, 2013. 
